\title{
Helicobacter pylori, gastric acid, and duodenal gastric metaplasia
}

In this issue, there are two studies examining the pathogenesis of gastric metaplasia within the duodenal bulb (DGM). On page 513, Harris et al examine the relation between DGM, $H$ pylori status, and gastric acid output. Their study involved healthy volunteers and duodenal ulcer patients, with and without current $H$ pylor $i$ infection. Acid output was measured basally and in response to stimulation with gastrin releasing peptide (GRP) and supraphysiological doses of pentagastrin. They found a significant direct correlation between the extent of DGM and gastric acid output measured by each of the above methods. The correlation was greater for basal and GRP stimulated acid output, which are both measures of physiological regulations of acid secretion, than for supraphysiological doses of pentagastrin, which measures only the maximal acid secretory capacity. The finding of a strong direct correlation between gastric acid output and degree of DGM supports the hypothesis that DGM develops in response to an increased duodenal acid load.

Harris et al also included data on the relation between $H$ pylori status and gastric acid secretion, though fuller details of this are presented in their earlier publication. ${ }^{1}$ Basal acid output, GRP stimulated acid output, and pentagastrin stimulated acid output were all increased in duodenal ulcer (DU) patients and this resolved, after eradication of the infection. The finding that $H$ pylori infection causes increased basal and GRP stimulated acid output in DU patients is consistent with the previous studies by El-Omar $e t a l^{2}$ and Moss and Calam. ${ }^{3}$ The fall in maximal acid output after eradication of $H$ pylori in DU patients has been noted in one previous study ${ }^{4}$ but not in others. $^{25}$

Despite the fall in gastric acid secretion after eradication of $H$ pylori infection, there was no statistically significant fall in the extent of DGM, though there was a trend in that direction. A recent study by Khulussi et al did observe a statistically significant $42 \%$ reduction in extent of DGM at six months after $H$ pylori eradication in DU patients. ${ }^{6}$

In the light of these findings, a relation between $H$ pylori infection, acid secretion, and DGM becomes apparent in DU patients; namely $H$ pylori infection stimulates increased acid secretion and the resulting increased duodenal acid load results in the development of DGM.

In retrospect, one possible weakness in this otherwise excellent study by Harris et al is their selection of $H$ pylor negative DU patients. These consisted predominantly of patients who had been cured of $H$ pylori infection some years earlier and whose ulceration had persisted or recurred. Resolution of DGM as shown in their study, occurs slowly, if at all, after eradication of $H$ pylori and the accompanying reduction in acid secretion. It may be inappropriate therefore to correlate the degree of DGM in these DU patients cured of $H$ pylori with their current acid status. Before eradication of their $H$ pylori infection their acid secretion will have been considerably higher and the degree of DGM metaplasia is therefore likely to reflect their previous high duodenal acid load. Consistent with this is the fact that two of these DU patients cured of $H$ pylori had very severe DGM (100\% and $72 \%)$ despite only modest acid output. Excluding the DU patients in whom $H$ pylori had been eradicated shows an even stronger association between DGM and basal and GRP stimulated acid output, which are the acid measurements that show greatest resolution after eradication of $H$ pylori. This is consistent with DGM being caused by longterm increased duodenal acid exposure and being slow to resolve after reduction of acid secretion.

In addition to increasing gastric acid, $H$ pylori might directly stimulate the progression of DGM by inducing inflammation of the duodenal mucosa. ${ }^{7}{ }^{8}$ Harris et al tried to test this hypothesis by seeing whether $H$ pylori positive subjects had more DGM than $H$ pylori negative subjects. They found that the degree of DGM was unrelated to $H$ pylori status and therefore concluded that the mechanism by which the infection produces DGM is likely to be entirely through its acid stimulatory effects. However, as already mentioned, their $H$ pylori negative DU subjects are an unsatisfactory group for performing correlations based on current status. After excluding these there are insufficient subjects of different $H$ pylori status and similar acid output to test for an acid independent relation between $H$ pylori status and severity of DGM. Consequently, this study does not clarify whether colonisation of DGM by $H$ pylori and the subsequent inflammation contributes to progression of DGM.

On page 508, Savarino et al report their study of the relation between gastric acidity and DGM. They examined $H$ pylori positive DU patients, 49 of whom had DGM and 22 of whom did not. They performed 24 hour intragastric $\mathrm{pH}$ in these two groups and in a group of non-ulcer controls in whom there was no information about their duodenal histology. The intragastric $\mathrm{pH}$ was lower in the DU patients than controls, but no difference could be detected between the patients with and without DGM. In the light of this finding, Savarino et al have come to the opposite conclusion to that of Harris et al, namely that gastric acid is not the major determinant of DGM.

How does one explain these different conclusions? The discrepancy between these results is probably explained by the different methods used to measure gatric acid status. Savarino et al measured only the acidity of the gastric juice. In contrast, Harris et al measured both its acidity and rate of secretion and were thus able to calculate gastric acid output. The strong positive correlation between DGM and gastric acid output but lack of correlation between DGM and gastric acidity shows that the rate of gastric acid secretion is probably a key factor in the development of DGM. This makes physiological sense as the amount of acid entering the duodenum will depend upon its rate of secretion by the stomach. It is worth remembering that no 
matter how highly acidic gastric juice may be, it cannot exert any adverse effects on the duodenal mucosa until it passes the pylorus, and the amount doing this will depend upon its rate of secretion by the stomach.

Intragastric $\mathrm{pH}$ metry has the further disadvantages of being a relatively insensitive means of measuring gastric acid status in the highly acidic stomach. This is shown by Savarino et al who observed that the 24 hour intragastric $\mathrm{pH}$ in their DU patients differed from that in their healthy volunteers by only $0.4 \mathrm{pH}$ unit. In contrast, Harris et al found that DU patients had a $400 \%$ increase in basal acid output and $300 \%$ increase in GRP stimulated acid output compared with healthy controls. This higher sensitivity of acid secretion tests versus $\mathrm{pH}$ measurement at low $\mathrm{pH}$ makes the former tests more suitable for detecting correlations between disease and high acid status.

It is interesting that the measures of acid status found to correlate most strongly with the extent of DGM - that is, basal acid output and GRP stimulated acid output are also the ones which are most markedly increased by $H$ pylori infection in DU patients. This shows that it is the disturbance of these physiological functions by $H$ pylori infection that results not only in the development of DGM but also in the development of actual duodenal ulceration.
KENNETH E L McCOLI Department of Medicine and Therapeutics, Gardiner Institute, Western Infirmary, Glasgow G11 6NT

1 Harris AW, Gummett PA, Misiewicz JJ, Baron JH. Eradication of Helicobacter pylori in patients with duodenal ulcer lowers basal and peak acid output to gastrin releasing peptide and pentagastrin. Gut 1996; 38: 663-7.

2 El-Omar E, Penman ID, Ardill JES, Chittajallu RS, Howie C, McColl KEL Helicobacter pylori infection and abnormalities of acid secretion in patients with duodenal ulcer disease. Gastroenterology 1995; 109: 681-91.

3 Moss SF, Calam J. Acid secretion and sensitivity to gastrin in patients with duodenal ulcer: effect of eradication of Helicobacter pylori. Gut 1993; 34: duodenal

4 Parente F, Maconi G, Sangaletti O, Minguzzi M, Vago L, Bianchi Porro G Behaviour of acid secretion, gastrin release, serum pepsinogen I, and gastric emptying of liquids over six months from eradication of Helicobacter pylori in duodenal ulcer patients. A controlled study. Gut 1995; 37: 210-5.

5 Gisbert JP, Boixeda D, Vila T, de Rafael L, Redondo C, Martin de Argila C. Basal and stimulated gastrin levels and gastric acid output five months after therapy for Helicobacter pylori eradication in duodenal ulcer patients. 7 Clin Gastroenterol 1996; 22: $90-5$.

6 Khulusi S, Badve S, Patel P, Lloyd R, Marrero JM, Finlayson C, et al. Pathogenesis of gastric metaplasia of the human duodenum: role of Helicobacter pylori, gastric acid, and ulceration. Gastroenterology 1996; 110: Helicobacter pylori, gastric acid, and ulceration. Gastroenterology 1996; 110: 452-8.

7 Wyatt JI, Rathbone BJ, Sobala GM, Shallcross T, Heatley RV, Axon ATR, t al. Gastric epithelium in the duodenum: Its association with Helicobacter pylori and inflammation. $\mathcal{F}$ Clin Pathol 1990; 43: 981-6.

8 Wyatt JI, Rathbone BJ, Dixon MF, Heatley RV. Campylobacter pylori and acid induced gastric metaplasia in the pathogenesis of duodenitis. $\mathcal{F}$ Clin Pathol 1987; 40: 841-8. 